\title{
Lifestyle, responsibility and justice
}

\author{
E Feiring
}

Correspondence to:

E Feiring, Postdoctoral research fellow, Department of Political

Science, University of Oslo, PO

Box 1097 Blindern, N-0317 Oslo,

Norway; eli.feiring@stv.uio.no

Received 7 September 2006

Revised 30 November 2006

Accepted 6 December 2006
Unhealthy lifestyle contributes significantly to the burden of disease. Scarce medical resources that could alternatively be spent on interventions to prevent or cure sufferings for which no one is to blame, are spent on prevention or treatment of (the risk of) disease that could be avoided through individual lifestyle changes. This may encourage policy makers and health care professionals to opt for a criterion of individual responsibility for medical suffering when setting priorities. The following article asks whether responsibility-based reasoning should be accepted as relevant for fair and legitimate healthcare rationing. The luckegalitarian argument that inequalities in health expectancies that derive from unchosen features of people's circumstances are unjust and should be compensated, while inequalities that reflect personal choices of lifestyle may not, is discussed. It seems that while a backward-looking interpretation of individual responsibility cannot be relevant as a criterion of priority setting, a forward-looking conception of responsibility may be approved.

Within all modern societies healthcare authorities are facing difficult priority setting problems. Various criteria for rationing medical intervention have been proposed due to scarcity of resources. Until now, individual responsibility for medical suffering has been given little attention in the public or in academic debate. This is about to change. As Alexander Cappelen and Ole Norheim have pointed out in a recent article in this journal, unhealthy lifestyle contributes increasingly to the burden of disease. A better understanding of the responsibility argument is important for the assessment of policies aimed at meeting this challenge. ${ }^{1}$ In this article the following question is addressed: should responsibility-based arguments be accepted as relevant to meeting healthcare rationing fairly and legitimately? I will argue that while a backward-looking conception of individual responsibility should not be endorsed, a forwardlooking notion of responsibility may be approved.

\section{RESPONSIBILITY AND JUST ALLOCATION OF HEALTHCARE}

There are both empirical and theoretical reasons for why it is time to ask whether people in developed countries should be held responsible for their health and if so, how a criterion of responsibility should be applied as a limit-setting device when deciding whether or not a particular medical intervention should be part of public healthcare and how to set priorities among patients. As reported by the World Health Organization (WHO), most of the risk factors contributing to the burden of disease can be attributed to unhealthy lifestyle. ${ }^{2}$ Thus, one of the major challenges for healthcare authorities in liberal-democratic welfare states seems to be the fact that scarce resources are spent on treatment of medical sufferings that, at least to some degree, could be avoided through individual lifestyle changes.

Theoretically, there has been a shift in the general ideal of equality of opportunity from the traditional ideal of equality of condition to an ideal of equality that incorporates responsibility by compensating individuals for unequal circumstances while holding them responsible for their choices. The view that egalitarianism is based on a concern with a choice-oriented view of responsibility may be labelled luck-egalitarianism. ${ }^{3}$ Although this view is expressed somewhat differently among scholars, the core ideas are as follows. ${ }^{4-6}$ The concern of distributive justice is "to eliminate so far as possible the impact on people's lives of bad luck that falls on them through no fault or choice of their own"? Inequalities generated by the individual's voluntary choices are, however, acceptable and do not give rise to redistributive claims on others. Nobody is required to mitigate the effects of these choices.

The principle of responsibility implies that society ought to distribute goods and burdens in a way that is luck-neutralising and choice-sensitive. When applied on issues of just allocation of healthcare, the principle suggests that inequalities in health expectancies that stem from differences in lifestyle that reflect personal priorities are justified, and might not be compensated. A backward-looking interpretation of individual responsibility for (high risk of) deviations from normal functioning would imply that people should be held responsible for their medical condition in virtue of their prior conduct. It is, however, not obvious exactly what this means. The answer to this question is highly important when deciding whether there are good reasons to accept a backward-looking conception of individual responsibility when making decisions on priority setting within healthcare.

\section{THE CASE OF OBESITY}

Consider the case of obesity. As reported by the $\mathrm{WHO}$, obesity (body mass index $>30$ ) has become an epidemic and leads to increased risks of coronary heart disease, stroke, type 2 diabetes, osteoarthritis, and several cancers. ${ }^{2}$ The increased incidence of obesity cannot be blamed on either environment or genetics alone. Increase in caloric intake and decrease in physical activity are primarily responsible for it, although genetic background, maternal weight, and socioeconomic status are important. ${ }^{8}$

Both prevention and treatment of obesity are necessary means to reduce risk of severe disease 
and premature death. ${ }^{9}$ For many, losing weight is difficult. It is shown that fewer than five percent of people who attempt diet and exercise recommendations succeed. ${ }^{10}$ Psychological intervention is often necessary to help obese patients initiate and maintain behaviour change. ${ }^{11-12}$ Alternatives are pharmacologic therapy for obesity, and surgery.

\section{SHOULD LIFESTYLE CHOICES AFFECT PRIORITY SETTING?}

Now, let us assume that we live in a developed country with a universal coverage healthcare system with no supplementary tier that is purchased by those who are best off in society. There is no private healthcare insurance available. Trivially, the assumptions of scarcity and opportunity costs apply. Public healthcare resources are scarce and time and technology invested to provide a given medical intervention always have an alternative usage within (and without) the public healthcare system.

We are engaged in the deliberation on whether a particular intervention if to treat obesity for the purpose of reducing risk $r 1$ of severe disease $x$ should be part of public healthcare, and whether information on lifestyle and body mass index should be given weight (if at all) when setting priorities among patients waiting for a particular medical intervention $i 2$ to treat a severe disease $x$ (associated with lifestyle-induced risk $r 1$ as well as non-lifestyle induced risks $r 2, r 3 \ldots$ ).

The following arguments are put forward. First, if obesity is rightly attributed to individual lifestyle choices, i1 should not be covered within the public healthcare system. Second, i2 should be allocated according to a priority-rule that assigns longer waiting time to patients suffering from $x$ as a result of individual lifestyle choices (contributing to $r 1$ ), than for patients suffering from $x$ as a result of factors not within their control (contributing to $r 2, r 3 \ldots$ ).

The luck-egalitarian mode of reasoning may explain the intuitions behind these arguments. If lifestyle preferences are formed under conditions of justice and circumstantial differences in opportunity to choose a healthy lifestyle are neutralised through preventive means, then outcomes that are suitably related to one's choices (option luck) need not be compensated. The individual may be asked to bear the costs of engaging in risky behaviour. ${ }^{13}$ Although it is difficult to avoid risk altogether, she may be held responsible for not choosing the least risky prospect. ${ }^{14}$ Differences in people's access to treatment should be allowed when they are due to differences in lifestyle choices. It seems, however, that it would not be reasonable to hold people wholly responsible for outcomes that reflect option luck in these matters. Obesity may not adequately explain why some get a (face a high risk of) severe disease $x$ and others do not, because (high risk of) disease is an outcome partly determined by occurrence of events we cannot reasonably avoid the possibility of (brute luck).

It may, then, be wrong to deny any claims on society to provide an intervention i1 to treat obesity for the purpose of reducing risk $r 1$ of severe disease $x$. Nevertheless, these claims would be weak and may be overridden by competing claims when allocating healthcare resources.

Accordingly, the obese patient suffering from $x$ should not be held wholly responsible for her situation at the sick bed and be denied treatment. Assigning longer waiting time for treatment to obese patients than to their normal-weight counterparts may be one way of holding people partly responsible for their lifestyle choices. To sum up:

If the individual can reasonably be held responsible for (high risk of) deviations from normal functioning due to obesity, she has weak claims on society to provide specialized medical intervention within a limited healthcare budget.

\section{DISCUSSION: INDIVIDUAL RESPONSIBILITY REJECTED?}

Do we have sufficient reason to accept limit-setting according to this line of argumentation as fair and legitimate? I think the answer is no. In general, the luck-egalitarian position has been criticised for a number of reasons that I cannot pursue in any depth here. ${ }^{35-21}$ Let me briefly make four points.

First, it appears to be a flaw to ground the idea of egalitarianism on the distinction between choices and circumstances. As Samuel Scheffler has pointed out, this distributive formula must be part of a larger normative theory. ${ }^{20}$ Unless the category of choice is explained as distinctive in a way that makes it a privileged indicator of the fairness or unfairness of an outcome, it is difficult to understand why it should have such a fundamental importance as it has within luck-egalitarianism. Second, the choice-circumstances dichotomy seems implausible, because choices may better be thought of as simultaneously autonomous and socialised. ${ }^{172021}$ It is hard to identify any action that is not partly determined by circumstance understood as the social contexts in which the individual finds herself or her traits of character (included the ability to choose). It is not obvious, then, what it means that someone may reasonably be held responsible for her actions. Third, although people may be held responsible for their choices in the sense of being open to moral criticism for negligence or high-risk behaviour, this does not imply that they are not entitled to any assistance. ${ }^{3} 1520$ Issues of what people are to be held responsible for should be distinguished from issues of how deserving they are. In Susan Hurley's words, responsibility cannot play a pattering role. ${ }^{18}$ Fourth, luck-egalitarianism may promote the wrong "ethos of equality". ${ }^{16}$ As Elizabeth Anderson has forcefully put the argument: ${ }^{3}$

(T)he social process of distinguishing responsible from irresponsible, deserving from non-deserving citizens is inherently disrespectful and unfair to all members of society (...). (T)aking the imperative of justice to be undoing the effects of all brute bad luck inherently erases the line between what is the legitimate concern of society and what should be left to individual discretion.

\section{Healthcare is a special good}

When considering the backward-looking concept of individual responsibility within the healthcare context, I think there are reasons external to the luck-egalitarian position that may explain why it is so important to pay attention to these critical points. The core of the argument is that healthcare is a special good and should not be allocated to eliminate the impact of bad brute luck or to ensure that everyone gets what they morally deserve. As Norman Daniels has pointed out, what makes healthcare special is its role in establishing fair equality of opportunity. ${ }^{22} 23$ The proper aim of healthcare allocation is to contribute to protect (age-relative) opportunity for participation in society on a roughly equal footing. Disability and disease reduce the range of opportunities to exert citizenship that people would otherwise enjoy. The idea of equal citizenship is part of the liberal-contractual notion of society as a fair system of cooperation among free and equal people. Equality is an ideal that governs the terms of cooperation, and is not solely a distributive notion. ${ }^{20}$ 
The implication of this argument is that healthcare allocation must be defended and criticised in terms of consideration that others, free and equal, have reasons to accept, given the fact of reasonable pluralism and on the assumption that those others are themselves committed to provide suitable justification. ${ }^{24}$ Citizens are entitled to make claims on one another by virtue of their status as citizens. This means that one needs to find reasons for just allocation that are compelling to all accordingly motivated - regardless of their diverse commitments, natural attributes or social starting-points.

\section{Rejecting the backward-looking conception of individual responsibility}

In my view, the luck-egalitarian underpinnings of the backward-looking responsibility conception fail to appreciate this concern. It is simply not reasonable that the distinction between choices and circumstances have fundamental importance for questions of how to ration scarce healthcare resources as in the case of obesity. The explanation is that the "irresponsible" minority can hardly assure itself that the preferences of the "responsible" majority rests on the kind of reason that even the minority must acknowledge as appropriate. Let me give two examples (that resemble the criticism against luck-egalitarianism made as point two and four described above).

The backward-looking responsibility conception tells us to find a way to split compensation between people according to which extent they can be held properly responsible for their choices. The diversion requires an explanation of what is to count as choice and what is to count as circumstance that must be acceptable to all. In the literature, there is vast disagreement on where to draw the line. ${ }^{20}$ What appears to be difficult in ideal theory is even more so in the context of healthcare where social and economic inequalities are very important in determining health expectancies. Obesity is not evenly distributed across the population. As Brian Barry has pointed out, poverty, class and income are key-determinates of obesity and weight-related disease..$^{25}$ It may not, then, be reasonable to hold that lifestyle choices are informed and deliberate in the way that ought to be conditions for personal responsibility.

Likewise, the decision on how to classify persons according to moral desert must be acceptable to all. There are at least two reasons why this requirement may be difficult to meet. To put focus on the distinction between choice and circumstances may encourage the state to view its disadvantaged citizens with distrust, as potential cheaters. ${ }^{16}{ }^{26}$ The obese patient may have to prove she suffers from an involuntary disadvantage and answer questions about her own life as well as her family background that may be intrusive. One example is that she may be asked to submit to genetic testing, which may reveal information she (and her relatives) prefers to remain in ignorance of. Further, the majority may be encouraged to make moralised judgments in order to classify persons according to the degree of irresponsibility of their choices of food and activity. Moral categories may then be used in a simplistic way which ignores the complexity of the situation. ${ }^{20}$

\section{A forward-looking conception of individual responsibility}

Would it be altogether wrong to consider individual responsibility when allocating scarce healthcare resources? Let us assume a deliberation process identical to the one described above. Remember the liberal-contractualist argument that the minority ought to assure itself that the preferences of the majority rest on the kind of reason that even the minority must acknowledge appropriate. This could mean to give priority to the worst off but only if significant health benefit is expected and treatment is cost-effective. Then the concept of medical need is interpreted according to both the pre-allocative and the expected post-allocative level of health. ${ }^{27}$

Even if this middle range priority position is indeterminate, I find it compelling. The reason is that it incorporates the concern for the most vulnerable without sacrificing greater health benefits to others. ${ }^{28}$ Giving priority to the most urgent cases without concern with efficacious use of limited resources may avoid abandonment of critically ill patients (which is likely to happen if maximising health benefit is all that matters) but only to the expense of the opportunities of health improvements of others.

Accordingly, the consideration of individual responsibility would not be relevant when deciding whether or not i1 should be part of public healthcare. If obesity is (rightly) regarded as a significant predictor of severe illness and premature death and treatment is scientifically proven to be effective and costeffective, treatment of obesity should be provided within public healthcare.

But when we ask if an obese patient suffering from $x$ should accept a longer wait than a normal-weight person to get access to elective medical intervention $i 2$, I think the notion of individual responsibility may come into play.

To see how, we must return to the criteria of priority setting. Severely ill patients who are likely to respond well to treatment (within given resource constraints) should, under the specified understanding of medical need, be given priority over patients less likely to benefit.

Several factors may reduce expected benefit of treatment. While the individual has little or no power to influence some of these factors, she may be in a position to improve others. Factors attributed to lifestyle are among the latter. If the obese patient suffering from $x$ does not change her lifestyle, then expected benefit from intervention $i 2$ decreases and the patient will be given lower priority on the waiting list.

TM Scanlon has argued that it seems that when a person has had an opportunity to avoid a certain outcome by choosing appropriately, this fact weakens her grounds for rejecting a principle that would make her bear the burden of that result. What matters is the value of the opportunity to choose that the person is presented with. ${ }^{15}$ I suggest that the obese patient suffering from $x$ should be asked to sign a contract of frequent medical follow-ups to help her lose weight (in the same token as smokers with chronic obstructive lung disease should be asked to get medical advice on how to quit smoking and alcohol abusers with liver disease on how to stop drinking). If the patient refuses, then she cannot reasonably complain to be given lower priority on the waiting list.

The point is not, then, to assess whether or not it would have been obtainable for one in the patient's circumstances to make greater effort to get a healthy lifestyle in the past. She may or may not have had less opportunity than others not to make bad choices. Rather, the point is that when resources are limited we owe it each other to do what we can to make medical treatment efficacious.

A priority scheme which includes the specified notion of responsibility may have unintended secondary consequences. ${ }^{27}$ Priority should be given according to the criteria of severity of disease and expected benefit of treatment. By giving lower priority to patients who are not expected to respond well to treatment due to continuous unhealthy lifestyle, the scheme 
may also have the secondary effect of systematically giving patients from low social status-groups low priority because unhealthy lifestyle is associated with low social status. But this would be the case only if patients from low social status groups tend to refuse to sign the contract more often than others.

We might say that the patient refuses to sign the contract because she does not really know what she is doing and that an unwillingness to comply should not be given weight when setting priorities. But this argument treats the patient as a less than an autonomous being. Given that respect for the autonomous choices of patients runs deep in modern healthcare, there are strong reasons to value the claim that competent and well-informed individuals are the best interpreters of their own interest and that they should be free to make choices others would regard as non-beneficial to them. ${ }^{29}$

Of course, the contract may be broken and the priority decision may repeat itself, or the patient may not maintain her behaviour changes. These facts do not imply that further treatment (if necessary) should be denied. But others may simply have stronger claims on assistance. Thus, the forwardlooking concept of responsibility described here is rather thin. It explains why responsibility-oriented arguments may be justified in a priority-setting context but it does not support the conclusion that people should be held substantively responsible for previous choices.

Would this interpretation of the responsibility principle reproduce the problems rendering luck-egalitarian approaches unjust? I think not. First, rather than serve as a basis for just priority setting, the interpretation of the principle of responsibility is derived from a specific understanding of how to distribute healthcare. Second, we do not have to rely on a choice-circumstance binary to specify which inequalities are acceptable and which are not. Third, the fact that the individual's medical need can be traced down to bad lifestyle does not imply that she should be denied healthcare. And fourth, I do not think it disrespectful to ask the individual to do what she can to change an unhealthy lifestyle to make treatment efficacious. Some may argue that it is unfair to add a burden upon those in medical need by asking them to sign a contract of medical follow-ups. The very question may even hurt the patient's feelings, because one implicitly explains the disease with a reference to lifestyle. I do not, however, find these arguments strong enough to abandon individual responsibility-based arguments when estimating expected benefit of treatment. When deciding on the terms on which we want to live with one another, it is reasonable to expect people to make do with their fair shares.

These are difficult issues, and I cannot discuss them further here. I have, however, provided a case for the claim that a forward-looking conception of individual responsibility may be approved.

\section{CONCLUDING REMARKS}

The liberal-contractual proposal for how to design deliberation to which persons are entitled to hold one another accountable about healthcare rationing puts constraints on the set of considerations that should be placed on the table when we ask how to allocate healthcare resources. As Norman Daniels has pointed out, what is important is to protect fair opportunity to participate in society and exert citizenship by meeting people's medical needs within resource constraints. ${ }^{30}$ The question of justice within healthcare does not, then, concern the neutralisation of luck. Responsibility-based arguments may come into play, but only in a forward-looking version.

Acknowledgements: Earlier drafts of this article have been presented at the workshop on Equality of Opportunity, ECPR Joint Sessions, Granada 2005, and at the workshop on Priority Setting in Global Health, University of Bergen, 2005. Thanks to all the participants. The article also benefited from comments of several friends and colleagues, among them Alexander Cappelen, Robert Huseby, Raino Malnes, and Ole Fr. Norheim. Thanks to Pierre Boitte and especially to Bob Brecher.

Funding: The work for this article was made possible by a postdoctoral research grant from the Research Council of Norway.

Competing interests: None declared.

\section{REFERENCES}

1. Cappelen A, Norheim OF. Responsibility in health care - a liberal egalitarian approach. J Med Ethics 2005;31:476-80.

2. World Health Organization. The world health report: reducing risks, promoting healthy life. Geneva: WHO, 2002.

3. Anderson ES. What Is the Point of Equality? Ethics 1999;109:287-337.

4. Arneson R. Equality of Opportunity for Welfare. Philosophical Studies 1989;56:7793.

5. Cohen GA. On the Currency of Egalitarian Justice. Ethics 1989:99:906-44.

6. Roemer J. Equality of opportunity. Cambridge, MA: Harvard University Press, 1998.

7. Arneson R. Luck Egalitarianism and Prioritarianism. Ethics 2000;110:339-49. Cf. Temkin L. Inequality. New York: Oxford University Press, 1993.

8. Miller J, Rosenbloom A, Silverstein J. Childhood Obesity. J Clin Endocrinol Metab 2004;89:4211-18

9. Mello MM, Studdert DM, Brennan T. Obesity - The New Frontier of Public Health Law. N Engl J Med 2006;354:2601-10.

10. Miller WC. How effective are traditional dietary and exercise interventions for weight loss? Med Sci Sports Exerc 1999;31:1129-34.

11. Wing RR, Tate DF, Gorin AA, et al. A Self-Regulation Program for Maintenance of Weight Loss. N Engl J Med 2006;335:1563-71.

12. Takeharu K, Atsushi K, Hisamichi A. Obesity and Public Health Law. N Engl J Med 2006;354:1283

13. Vallentyne P. Brute Luck, Option Luck, and Equality of Initial Opportunities. Ethics 2002;112:529-57.

14. Sandbu M. On Dworkin's brute-luck-option-luck distinction and the consistency of brute-luck egalitarianism. Politics, philosophy \& economics 2004;3:283-312.

15. Scanlon TM. What We Owe to Each Other. Cambridge MA: Harvard University Press, 1998.

16. Wolf J. Fairness, Respect, and the Egalitarian Ethos. Philosophy \& Public Affairs 1998;27:97-122.

17. Mason A. Equality, personal responsibility and gender socialization. Proceedings of the Aristotelian Society 2000;100:227-46.

18. Hurley S. Roemer on Responsibility and Equality. Law and Philosophy 2002;21:3964.

19. Scheffler S. What is Egalitarianism? Philosophy \& Public Affairs 2003;31:5-39.

20. Scheffler S. Choice, circumstance, and the value of equality. Politics, philosophy \& economics 2005; 4:5-28.

21. Phillips A. "Really" Equal: Opportunities and Autonomy. The Journal of Political Philosophy 2006;14:18-32.

22. Rawls J. Justice as Fairness. A restatement. Cambridge, Mass: Harvard University Press, 2001.

23. Daniels N. Just Health Care. Cambridge: Cambridge University Press,1985.

24. Cohen J. Democracy and Liberty. In: Elster J (ed).Deliberative Democracy. Cambridge: Cambridge University Press, 1998.

25. Barry B. Why Social Justice Matters. Cambridge, UK: Polity Press, 2005.

26. Kymlicka W. Contemporary Political Philosophy. An Introduction. Oxford: Oxford University Press, 2002.

27. Elster J. Local Justice. How Institutions Allocate Scarce Goods and Necessary Burdens.New York: Russel Sage Foundations, 1992.

28. Daniels N, Sabin JE. Setting Limits Fairly: Can We Learn to Share Medical Resources? New York: Oxford University Press, 2002.

29. Beauchamp TL, Childress JF. Principles of Biomedical Ethics. New York: Oxford University Press, 1994.

30. Daniels N. Justice, Health, and Healthcare. The American Journal of Bioethics 2001;1:2-16. 